\title{
Right ventricle-pulmonary artery conduit with intake port in the Norwood procedure
}

\author{
Ryo Aeba, MD, and Ryohei Yozu, MD, Tokyo, Japan
}

The surgical management of hypoplastic left heart syndrome has been evolving rapidly over recent years. Norwood stage I palliation using a right ventricle-pulmonary artery (RV-PA) conduit instead of the modified Blalock-Taussig shunt has a theoretic advantage: The higher diastolic pressure and coronary perfusion pressure in the right ventricle compared with the systemic artery may result in more stable early postoperative hemodynamics. ${ }^{1}$ However, several ventriculotomy-related complications may occur with this technique, including impaired ventricular function, reobstruction, pseudoaneurysm formation, and arrhythmia. ${ }^{2}$ To prevent this, we developed a novel method for proximal conduit anastomosis, involving the use of an intake port, without the need for myocardial resection.

\section{SURGICAL TECHNIQUE}

Before skin incision, the RV-PA conduit is created on the back table (Figure 1). A 5-mm ringed expanded polytetrafluoroethylene (ePTFE) tube graft (WL Gore \& Associates, Flagstaff, Ariz) conduit is trimmed to approximately $50 \mathrm{~mm}$ of the ringed portion. A cuff is also tailored from the nonringed portion of the same conduit. ${ }^{1}$ Fibrin glue is used as a sealant for the cuff-graft suture line. Another piece of ringed tubing is trimmed to $8 \mathrm{~mm}$ (length) with 3 rings and attached to the spread-shaped tail of a Nelaton catheter (Covidien Japan, Fukuroi, Japan), which is trimmed to match the 5-mm diameter of the ringed conduit, using 7-0 polypropylene sutures. A 5-cm-long 7-0 polypropylene suture is attached to the other end of the conduit.

Cardiopulmonary bypass is established with dual arterial perfusion through the $3.5-\mathrm{mm}$ ePTFE graft placed on the right innominate artery and the descending aorta through the ductus arteriosus, and bicaval venous drainage (Figure 2). Any previously placed pulmonary arterial bands are removed. The pulmonary trunk is divided, and the previously fashioned RV-PA conduit is anastomosed to the distal opening of the pulmonary trunk. When the

From the Division of Cardiovascular Surgery, Keio University, Tokyo, Japan.

Disclosures: Authors have nothing to disclose with regard to commercial support.

Received for publication Feb 14, 2012; revisions received April 10, 2012; accepted for publication June 12, 2012; available ahead of print July 6, 2012.

Address for reprints: Ryo Aeba, MD, Division of Cardiovascular Surgery, Keio University, 35 Shinanomachi, Shinjuku, Tokyo 160-8582, Japan (E-mail: aebajp@ gmail.com).

J Thorac Cardiovasc Surg 2012;144:1260-2

0022-5223/\$36.00

Copyright (c) 2012 by The American Association for Thoracic Surgery

http://dx.doi.org/10.1016/j.jtcvs.2012.06.022

patient's rectal temperature reaches $25^{\circ} \mathrm{C}$, cardioplegic cardiac arrest is induced and bypass is switched to selective cerebral perfusion. Direct anastomosis is used for the posterior aspect of the neoaortic reconstruction. Then a small $(<3 \mathrm{~mm})$ stub wound is created in the ventricular wall, the location of which is guided by direct visualization from the ventricular cavity through the pulmonary valve, to exactly $5 \mathrm{~mm}$ below the pulmonary valve annulus. No myocardial resection is performed. A pair of forceps is negotiated through the stub wound to the outside of the opening of the pulmonary trunk and used to grasp the head of the Nelaton catheter. The second 3-ringed conduit is then positioned in the ventricular wall by withdrawing the Nelaton catheter. The traction suture on the other end of the Nelaton catheter is used for tugging in the opposite direction. The retaining sutures are cut to remove the Nelaton catheter. A few stay stitches are used to suture the epicardial incision. Then, anterior anastomosis of the neoaorta is completed with or without a small amount of autologous pericardial patch augmentation. Myocardial reperfusion and whole-body perfusion are reestablished with rewarming. The RV-PA conduit is placed to the right side of the neoaorta for Fontan-track cases and the left side for biventricular repair track cases. The conduit length is finetuned, and the cut end is slightly beveled. The proximal anastomosis of the RV-PA conduit is completed with a 7-0 polypropylene suture drawing the 2 ePTFE grafts and epicardial incision together.

This procedure has been used for 3 patients at Keio University, none of whom had signs of postoperative arrhythmia. Early and follow-up echocardiography and angiocardiography showed intact ventricular-wall motion, no de novo tricuspid or neoaortic valve regurgitation or ventricular pseudoaneurysm formation, and a widely open proximal anastomosis of the RV-PA conduit (Figure 3).

\section{DISCUSSION}

Many centers have adopted the RV-PA conduit modification for Norwood stage I palliation on the basis of the theoretic advantage associated with the higher diastolic pressure thus achieved. ${ }^{2}$ The main concern with the RVPA conduit is the potential for ventricular myocardial resection of the single ventricular physiology.

Proximal stenosis of the RV-PA conduit is the most notable complication and may lead to sudden death. ${ }^{3}$ Early development of this complication after operation may occur because of inadequate ventricular resection. It may also 


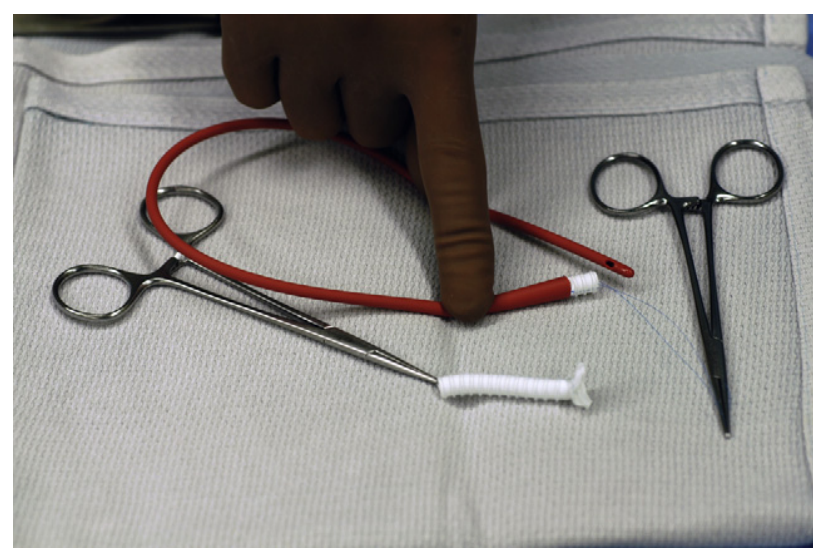

FIGURE 1. Back table preparation of the right ventricle to pulmonary artery conduit.

occur later because of endocardial proliferation, ventricular hypertrophy, or both. To date, all reports dealing with RVPA conduits have advocated the excision of the piece of myocardial tissue underlying the ventricular incision using a scalpel, scissors, or vascular punch to prevent this complication. However, this minor, yet significant, loss of ventricular myocardial tissue carries the risk of ventricular dysfunction. ${ }^{4}$ In contrast, our technique allows sparing of the myocardial tissue by using a Nelaton catheter as a dilator; stenosis is unlikely to occur in patients treated using this method because the intake port should prevent myocardial tissue involvement at the proximal end, both in the early and midterm stages after operation. The Loma Linda group recently proposed a modification involving ventricular fixation..$^{5}$ Although their technique has the same advantage with an intake port as ours, their modification is still associated with a high risk of myocardial resection-related complications.

The traumatized rough surface of the myocardial tissue is likely to generate some scar tissue that may cause ventricular arrhythmia. Our technique minimizes the formation of this rough surface, which may contribute to minimizing the risk of arrhythmia late after surgery. Pseudoaneurysms also can form in patients with a conventional RV-PA conduit ${ }^{6}$ because the proximal anastomosis over the myocardial excision site involves less myocardial tissue and therefore less anastomosis strength. In our technique, the shear stress at the proximal anastomosis should be reduced because the intramural portion of the ringed conduit is tightly bound to the myocardial tissue, and conductance of ventricular pressure should be attenuated at the epicardial surface. With our modification, damage to the tricuspid and pulmonary, or neoaortic, valves is avoidable by ventriculotomy site guidance via direct visualization from the inside of the ventricular cavity.

From a technical viewpoint, the conventional method requires the time-consuming step of myocardial resection, and determination of the end point is largely subjective, whereas our novel method is technically easier and reproducible and should result in higher predictability and stability of pulmonary flow after surgery.

\section{CONCLUSIONS}

We have developed a novel technique for conduit placement in the ventricular wall using an intake port, without the need for myocardial resection. This technique may
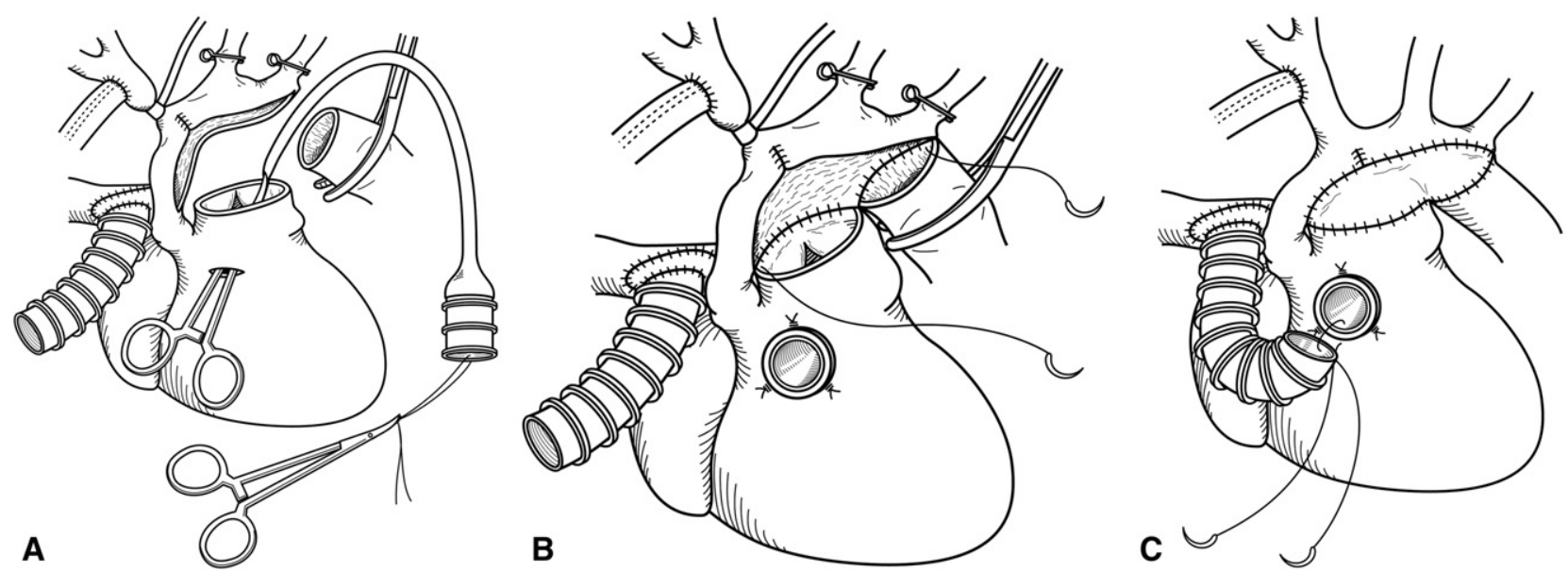

FIGURE 2. A, Small $(<3 \mathrm{~mm})$ stub wound is created in the ventricular wall, the location of which is guided by direct visualization from the ventricular cavity through the pulmonary valve, to exactly $5 \mathrm{~mm}$ below the pulmonary valve annulus. No myocardial resection is performed. A pair of forceps is negotiated through the stub wound to the outside of the opening of the pulmonary trunk and used to grasp the head of the Nelaton catheter (Covidien Japan, Fukuroi, Japan). B, The second 3-ringed conduit is positioned in the ventricular wall by withdrawing the Nelaton catheter. The traction suture on the other end is used for tugging in the opposite direction. The retaining sutures are cut to remove the Nelaton catheter. A few stay stitches are used to suture the epicardial incision. C, The conduit length is fine-tuned, and the cut end is slightly beveled. The proximal anastomosis of the right ventricle to pulmonary artery conduit is completed by suturing the 2 grafts and epicardial incision together. 

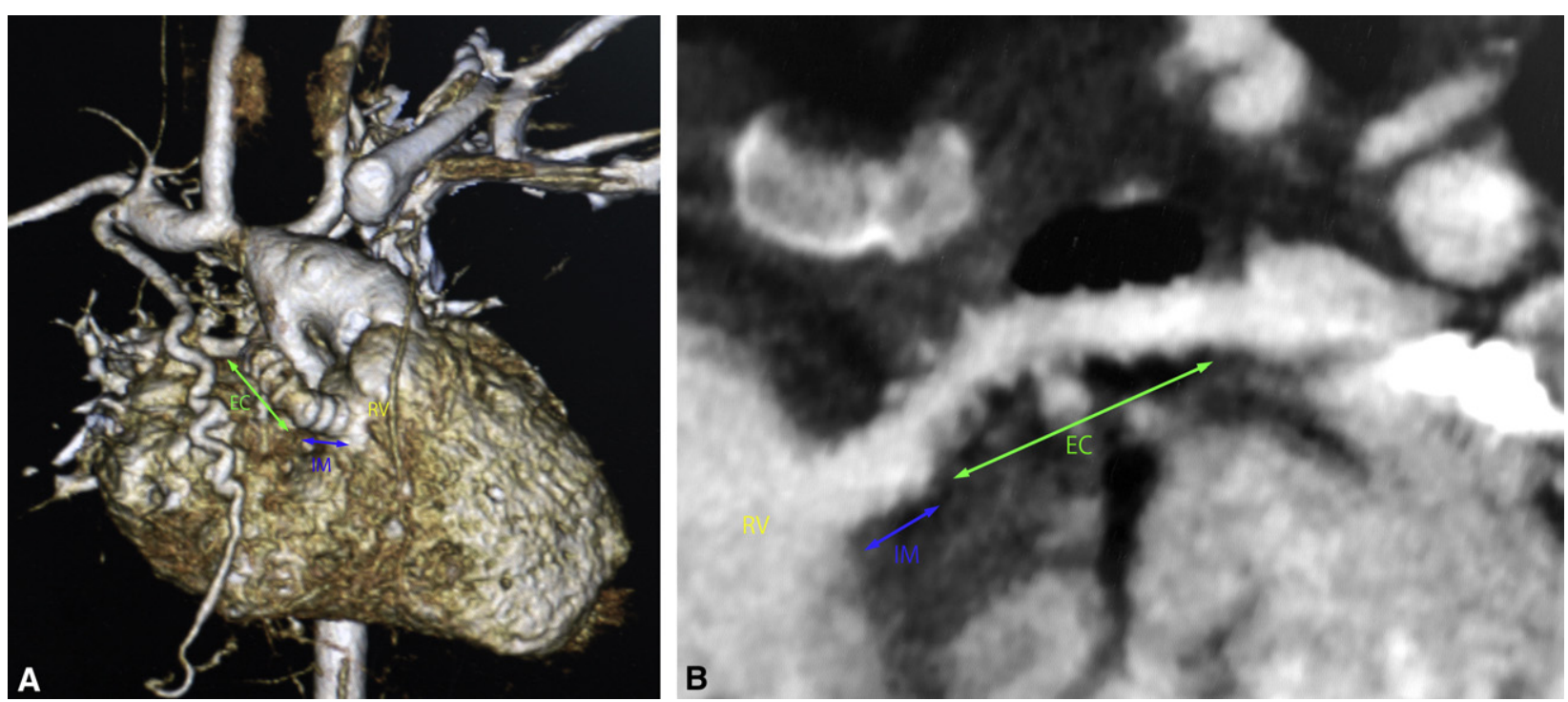

FIGURE 3. Follow-up computed tomography angiocardiogram in a patient 10 months after surgery showing the widely open proximal anastomosis and no ventricular pseudoaneurysm formation. A, Multidetector volume-rendering image (front view). B, Multiplanar reconstruction image of the conduit lumen. $E C$, Extracardiac portion of the conduit; $I M$, intramural portion of the conduit; $R V$, right ventricle.

make the creation of conduit inflow technically easier, minimally time-consuming, and highly reproducible, and minimize the risk of several potential ventriculotomyrelated complications, which augments an inherent advantage of the RV-PA conduit for Norwood stage I palliation.

\section{References}

1. Sano S, Ishino K, Kado H, Shiokawa Y, Sakamoto K, Yokota M, et al. Outcome of right ventricle-to-pulmonary artery shunt in first-stage palliation of hypoplastic left heart syndrome: a multi-institutional study. Ann Thorac Surg. 2004;78: 1951-8.
2. Reemtsen BL, Pike NA, Starnes VA. Stage I palliation for hypoplastic left heart syndrome: Norwood versus Sano modification. Curr Opin Cardiol. 2007;22:60-5.

3. Nigro JJ, Bart RD, Derby CD, Sklansky MS, Starnes VA. Proximal conduit obstruction after Sano modified Norwood procedure. Ann Thorac Surg. 2005;80:1924-8.

4. Hasaniya NW, Shattuck H, Razzouk A, Bailey L. Modification of ventricular-to pulmonary shunt to minimize proximal conduit obstruction after stage I Norwood reconstruction. Ann Thorac Surg. 2010;89:e4-6.

5. Tanoue Y, Kado H, Shiokawa Y, Fusazaki N, Ishikawa S. Midterm ventricular performance after Norwood procedure with right ventricular-pulmonary artery conduit. Ann Thorac Surg. 2004;78:1965-71.

6. Cua CL, Sanghavi D, Voss S, Laussen PC, del Nido P, Marshall A, et al. Right ventricular pseudoaneurysm after modified Norwood procedure. Ann Thorac Surg. 2004;78:e72-3

\title{
Papillary heads "optimization" in repairing functional mitral regurgitation
}

\author{
Masashi Komeda, MD, PhD, Yutaka Koyama, Shunsuke Fukaya, and Hideki Kitamura, Nagoya, Japan
}

\footnotetext{
From the Department of Cardiovascular Surgery, Nagoya Heart Center, Nagoya, Japan.

Disclosures: Authors have nothing to disclose with regard to commercial support. Received for publication April 13, 2012; revisions received May 21, 2012; accepted for publication June 15, 2012; available ahead of print Aug 10, 2012.

Address for reprints: Masashi Komeda, MD, PhD, Department of Cardiovascular Surgery, Nagoya Heart Center, 1-1-14 Sunadabashi, Higashi-ku, Nagoya 461-0045, Japan (E-mail: komeda@ heart-center.or.jp).

J Thorac Cardiovasc Surg 2012;144:1262-4

$0022-5223 / \$ 36.00$

Copyright (C) 2012 by The American Association for Thoracic Surgery

http://dx.doi.org/10.1016/j.jtcvs.2012.06.038
}

During surgery for functional mitral regurgitation (FMR), tethering of the posterior mitral leaflet (PML) is a major cause of residual or recurrent FMR, especially after aggressive annuloplasty. ${ }^{1}$ We have previously described the concept of a novel repair technique and echocardiographic method. ${ }^{2}$ We report on the techniques and clinical outcomes.

\section{METHODS}

A total of 16 patients (mean age, $67.8 \pm 0.9$ years; 12 men, 6 with ischemic cardiomyopathy and 10 with nonischemic cardiomyopathy) 